\title{
VERIFICATION OF THE PROCEDURE OF MATRIX DECIMATION (PMD) DURING THE TEST ON THE HARMONIC EXTORTION POSITION IN THE VEHICLE INSPECTION STATIONS
}

\author{
Janusz Gardulski \\ Silesian University of Technology, Faculty of Transport \\ Department of Automotive Vehicle Construction \\ Krasińskiego Street 8, 40-019 Katowice, Poland \\ e-mail: janusz.gardulski@polsl.pl
}

Pawel Sobczak

e-mail:sobczak.pawel@o2.pl

\begin{abstract}
Personal cars are the largest group of vehicles on the road. Every year a significant increase in this group of vehicles enforces the need to shorten the time of the study of the technical condition on vehicle inspection stations. One of the major components checked during the inspection is vehicle suspension that has a decisive influence on the comfort and safety.

Currently, vehicle inspection stations to assess the condition of the suspension mainly use EUSAMA method, which allows obtaining approximate results.

The paper presents the verification of the effectiveness and operation of the developed method called Procedure of Matrix Decimation (PMD), which allows for useful application of research results using FFT spectral analysis of nonstationary, transient signals recorded on the vehicle during the EUSAMA test method.

Verification of this method of signal processing was done with the use of vibration signals recorded on the vehicle during the EUSAMA test method on vehicle inspection stations. It consists of a comparison of the FFT spectra obtained for the secondary signal (after processing method based on PMD) with STFT analyzes made for the original signal.
\end{abstract}

Keywords: personal cars, suspension, shock absorbers diagnosis, vibroacoustic

\section{Introduction}

One of the main components of a vehicle having a direct impact on the comfort and safety is suspension of the vehicle $[1,2,4]$. Suspensions of modern cars are made of elastic elements, damping, and metal-rubber connectors. The used elastic elements are mainly coil springs with nonlinear characteristics, however, as the damping elements are used almost exclusively non-linear dampers, with asymmetric damping characteristics.

In the course of mandatory testing on vehicle inspection stations test of technical condition of the suspension are included. In the first phase of research are carried out organoleptic inspection of the suspension, followed by a device commonly known as "shredders". When properly passed preliminary tests then carried out to control the technical condition of shock absorbers built in the vehicle. Test methods used in the stations are built shock absorbers testing methods in the vehicle and can be divided into methods:

a) the free vibration,

b) forced vibrations.

The first of these groups due to the low accuracy of measurement results is not practically applied. Commonly used methods are forced vibrations of which the most common way is EUSAMA method developed by the European Association of Shock Absorber Manufacturer. This 
method involves determining the percentage of adhesive strength of the car wheels to the board to enforce the position and is determined by relationship:

$$
W E=\frac{\begin{array}{l}
\text { minimum value of apparent stress to the disc wheel position } \\
\text { during the occurrence of resonance }
\end{array}}{\begin{array}{l}
\text { value of the static wheel load to the disc position } \\
\text { determined for a fixed plate }
\end{array}}[\%] \text {. }
$$

Evaluation of the technical condition of shock absorber is based on the reference measurement result obtained for the rating scale shown in Tab. 1:

Tab. 1. The grading scale used in the EUSAMA method [1,2]

\begin{tabular}{|c|c|}
\hline WE value [\%] & Rating \\
\hline $60-100$ & Very good \\
\hline $40-59$ & Good \\
\hline $20-39$ & Satisfactory \\
\hline $0-20$ & Bad \\
\hline
\end{tabular}

EUSAMA method has several drawbacks, which include:

- school evaluation system,

- a wide range of interval,

- lack of identification of damage,

- the ambiguity of the results of measurement to assess adequately (EUSAMA recommended in this case the shock absorber removal and examination of the position of the indicator test stand).

The ambiguity of the results of measurements and the lack of identification of such damage is shown in [4]. In Fig. 1 presented EUSAMA index value obtained for different values of fluid leak in shock absorber.

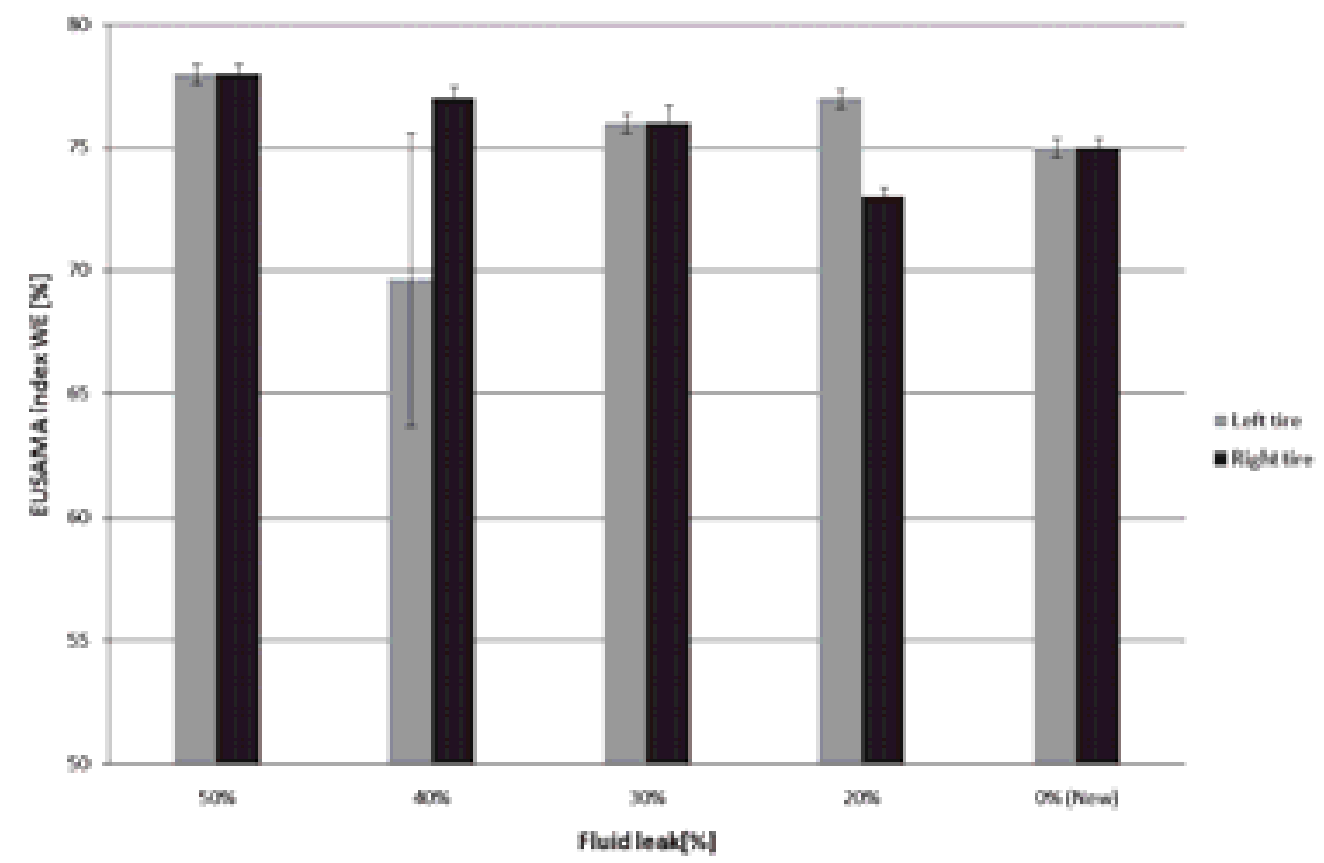

Fig. 1. EUSAMA index values as a function of fluid loss obtained for the Fiat Seicento 900 front suspension - own work based on [3]

As shown in Fig. 1 for the programmed defects obtained a high, close EUSAMA index value that specifies the technical state of shock as very good. 
This flaw makes it necessary to seek new and better methods of diagnosis, which made it possible to obtain more accurate and reliable results.

\section{Method of analysis}

The methods of obtaining the correct results of the analysis methods are based on an analysis of vibration signals from the test object (vibroacoustic methods). During a bench test vehicle is subjected EUSAMA vibrations, which can be divided into 3 phases:

1) phase of the run position above the resonance frequency of the vehicle masses,

2) the maintenance phase of the oscillation of fixed frequency oscillation (about $25[\mathrm{~Hz}]$ ) measurement of the stationary phase,

3) the phase range, in which cut-off position of the measurement, while the vehicle passes through all the resonance frequencies of the masses of their own.

The vibrations of the vehicle can be registered and subjected to appropriate analysis.

\section{Test and measuring track}

Tests were conducted on a FWT-1 Cartec company, making the measurement by EUSAMA method. The test stand is built on vehicle inspection station in Myslowice. The object of this study was the Fiat Seicento 900 rear suspension, which is shown schematically in Fig. 2.

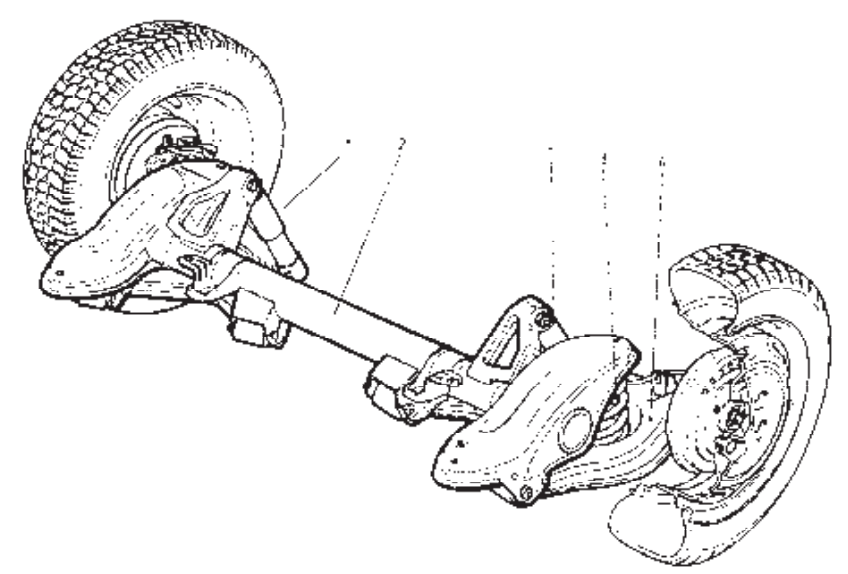

Fig. 2. Fiat Seicento 900 rear suspension [7]: 1 - telescopic shock absorber, 2 - beam suspension, 3 - cylindrical helical spring, 4 - longitudinal arm dragged

Acceleration vibration measurement path, which is shown schematically in Fig. 3, was used in the study.

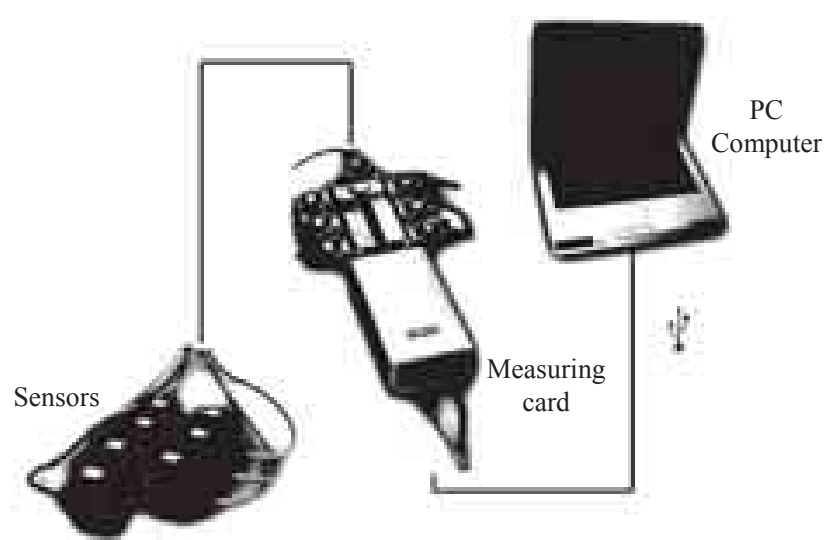

Fig. 3. The measuring vibration system [4, 5] 
Signals from the measuring board position, the vehicle (unsprung and the sprung mass) were recorded in the study. Place of attaching sensors of sprung (body) and unsprung (suspension) mass of the vehicle are shown in Fig. 4.

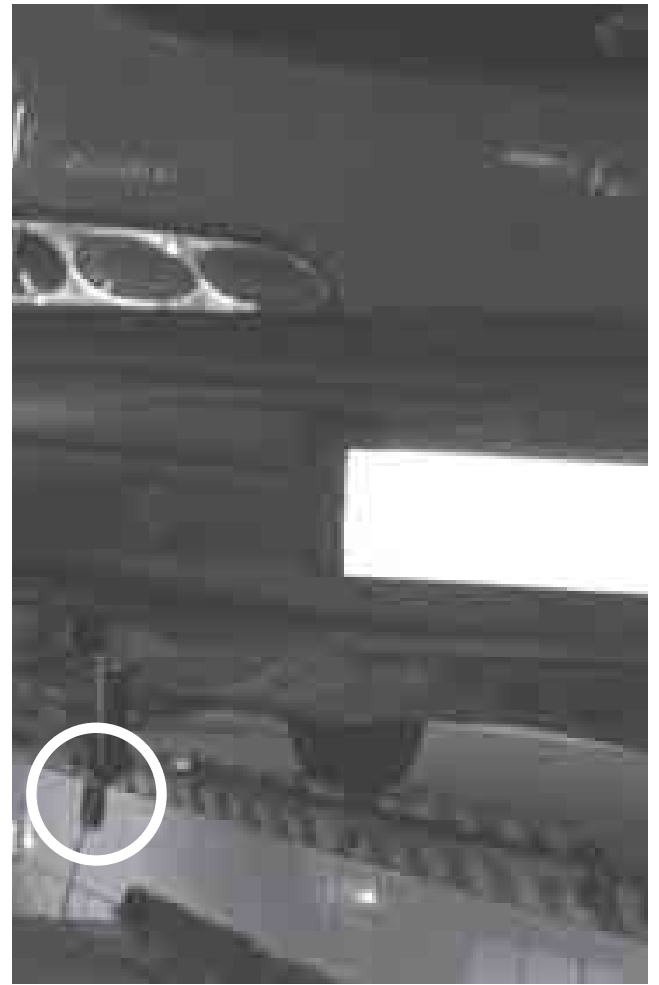

a) unsprung mass sensor

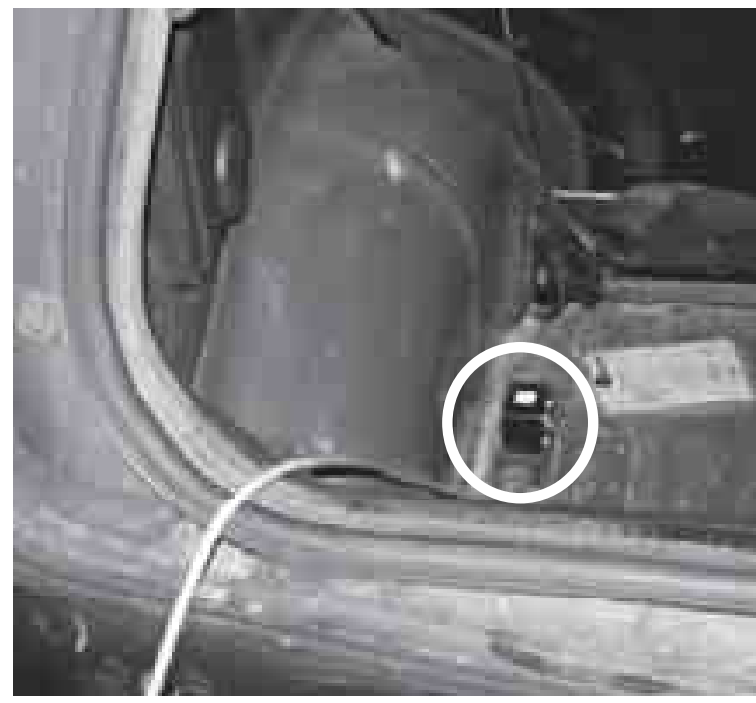

b) sprung mass sensor

Fig. 4. Place of attaching sensors of sprung (body) and unsprung (suspension) mass of the vehicle

The study was conducted using a modified shock absorber structure, which enabled programming a fluid loss in the range of 50 to $100 \%$ filling of the nominal value. Example of shock absorber filling process is shown in Fig. 5.

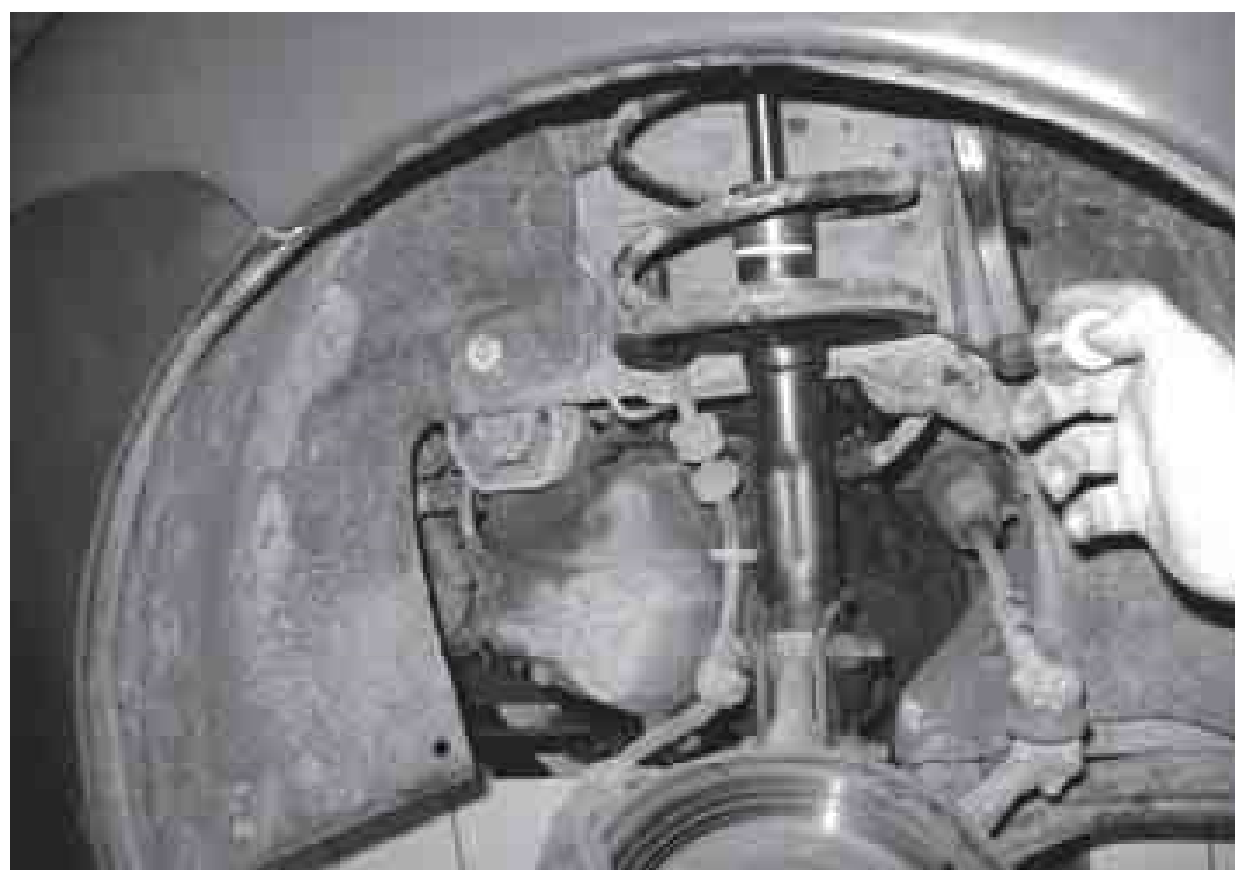

Fig. 5. Shock absorber filling process 


\section{Development of recorded vibration signals}

Vibration acceleration signals obtained were appropriate treatment. During the study were recorded the entire time courses (running, stationaryphase, running out) and to further processing were subjected the fragments of the signal that were recorded at the running out of test stand.

The recorded vibration signals are nonstationary, transients signals and therefore they can not be effectively analyzed using FFT without previous signal processing. To process the signals were used algorithm which was implemented in the program, described in [4]. Algorithm is called Procedure of Matrix Decimation (PMD).

The PMD algorithm performs automatic conversion of the original signal with a varying number of samples per period, into the secondary signal with a fixed number of samples per cycle. This number is proportional to the number of samples of the shortest cycle of the original signal. Signal conversion is done using decimation. Decimation factor is chosen individually for each cycle of the signal according to the formula [4]:

$$
d e c_{i}=c \frac{o k_{i}}{L_{\min }}, \text { where } \operatorname{dec}_{i} \in C^{+},
$$

where:

$d e c_{i}$ - decimation factor of the i-th cycle of the original signal (a row of the matrix formed),

$c$ - constant value (increasing decimation factor),

$o k_{i}$ - number of samples contained in the i-th cycle of the original signal,

$L_{\min }-$ minimum number of samples in the signal (the length of the shortest cycle of the original signal).

Automaticity is achieved by the automatic processing of location signals the beginning of each cycle, which is going through zero. The obtained information about the beginnings of successive cycles allowed the signal division into cycles counts the number of samples in each cycle, record the signal in the matrix in which each next line is saved for another signal cycle. Making the decimation of the signal stored in the array (hence the name of the method) and the creation of the secondary signal, which is a quasi-stationary signal. PMD algorithm developed method is shown in Fig. 6.

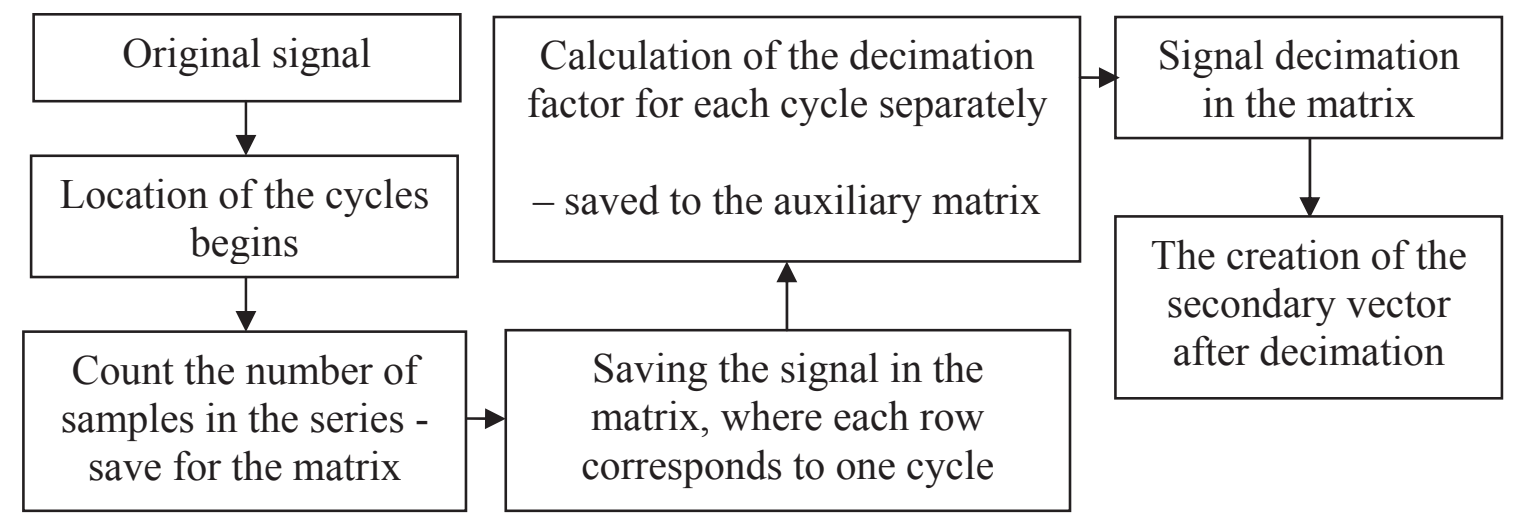

Fig. 6. PMD algorithm [4]

The effectiveness of PMD method in the analysis of non-stationary, transient signals was verified by simulation and laboratory tests which are described, among others in $[4,5]$.

Then obtained secondary signals were subjected to vibroacoustic analysis.

\section{Analysis of test results}

Primary and secondary signals that are quasi-stationary signals were subjected to analysis, the result of which has been adopted estimator charts changes in the function of shock absorber fluid loss. The paper presents results of analyzes obtained for the signals of acceleration of the vehicle body. 
In Fig. 7 are shown examples of comparison for the timing of primary and secondary body vibration acceleration signals in the running out phase of test stand.
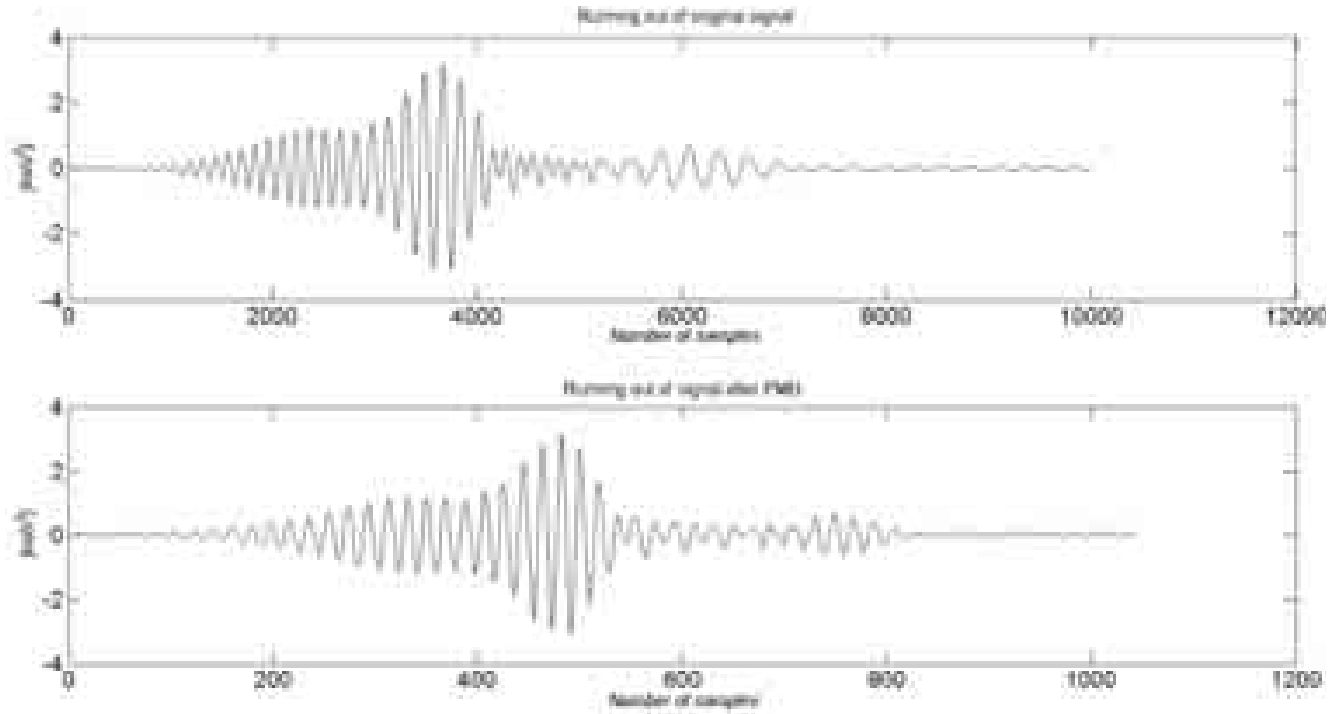

Fig. 7. Comparison of time-body vibration acceleration signal after filtering in the frequency of resonance of the unsprung masses - filling 50\%: Top: primary signal, Bottom: secondary signal - after treatment with PMD

All body vibration acceleration signals before further processing were subjected to filtration in the resonance frequency of the unsprung masses of the vehicle. Signals were subjected to the following analysis:

a) STFT analysis of the original signal,

b) FFT analysis of the signal after treatment with PMD.

The maps obtained signals after the STFT time-frequency and the FFT spectra of the PMD value of the maximum amplitudes were read in the resonance frequency of the unsprung masses of the vehicle. Sample results of the STFT and FFT signal after PMD are shown in Fig. 8.

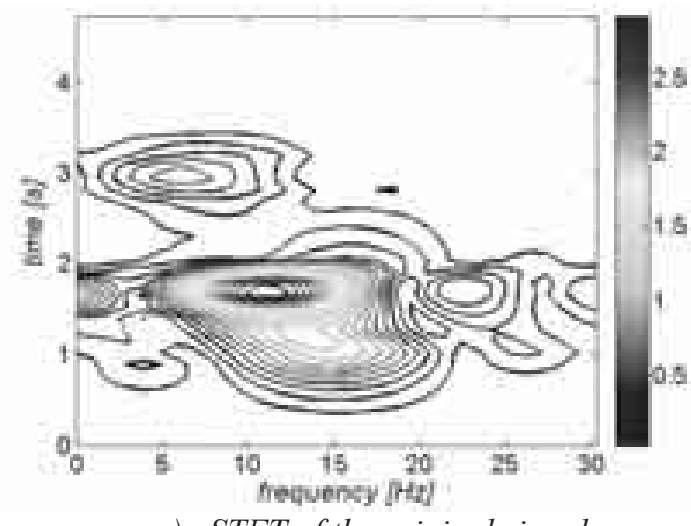

a) STFT of the original signal

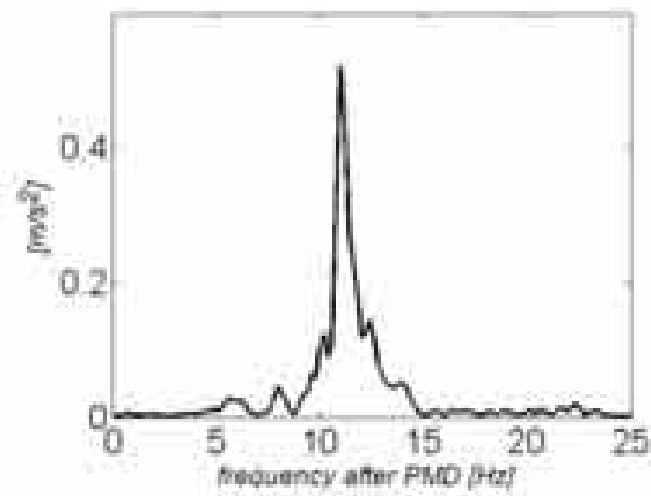

b) FFT of the signal after PMD

Fig. 8. Analysis of the STFT and FFT obtained for body vibration acceleration signal after filtering the resonance frequency of the unsprung masses - filling $50 \%$

As shown in Fig. 8 PMD, treatment allows obtaining the FFT spectrum with very high spectral selectivity and the correct location of the resonance frequency.

Figure 9 shows the results of the maximum body accelerations in the running out of test stand for resonance frequency of the unsprung masses obtained from the STFT analysis, while Fig. 10 shows the results of the maximum body accelerations in the running out of test stand for resonance frequency of the masses unsprung obtained by FFT of the signal after PMD. 


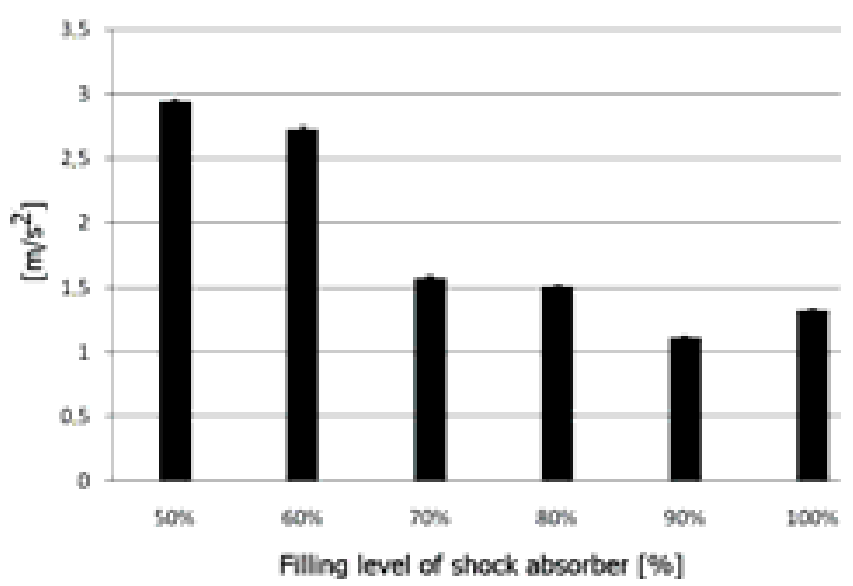

Fig. 9. The maximum value of acceleration in the running out of test stand obtained for the resonance frequency of the unsprung masses versus the shock absorber fluid loss - STFT analysis

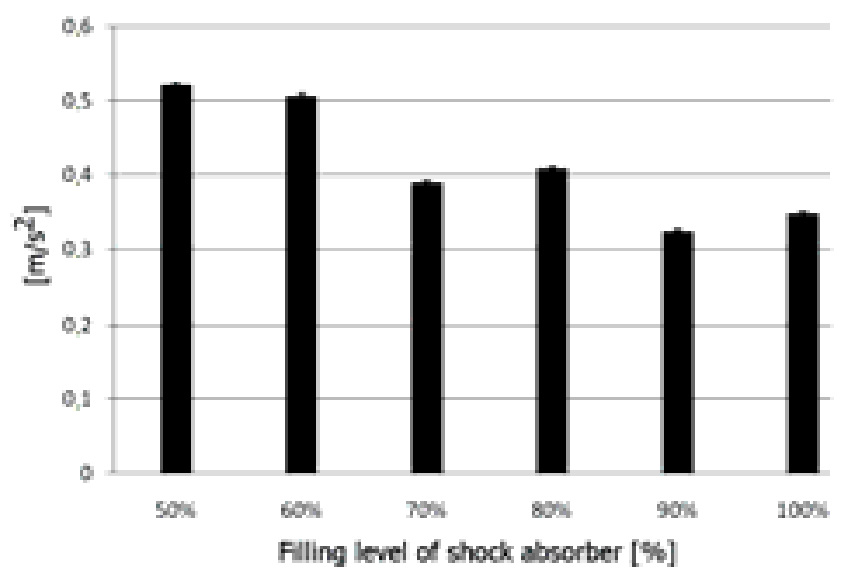

Fig. 10. The maximum value of acceleration in the running out of test stand obtained for the resonance frequency of the unsprung masses versus the shock absorber fluid loss - FFT analysis of the signal after PMD

In addition to the secondary signals containing several estimates were calculated from which good measures showing the sensitivity of the diagnostic features of shock absorbers fluid loss were chosen. Fig. 11a shows a graph of RMS changes, while the graph in Fig. 11b changes in the rate obtained for the peak coefficient vibration acceleration signals of the body in the running out of test stand for resonance frequency of the unsprung masses.

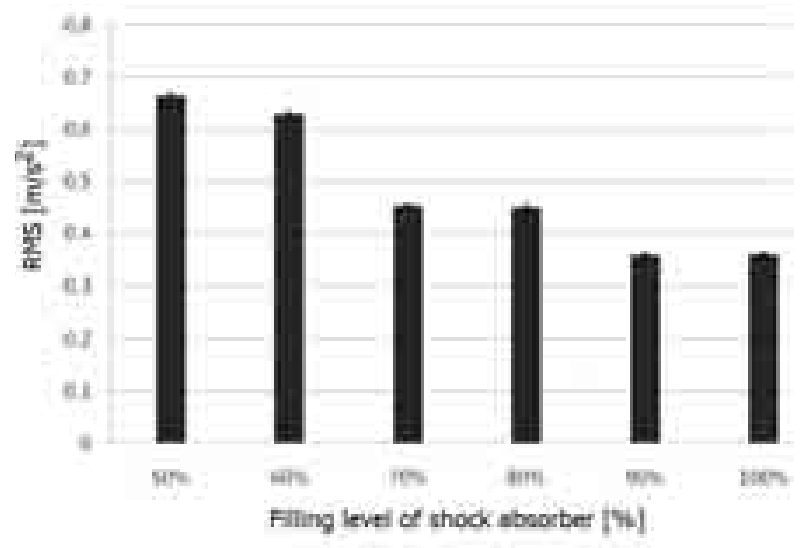

a) RMS value

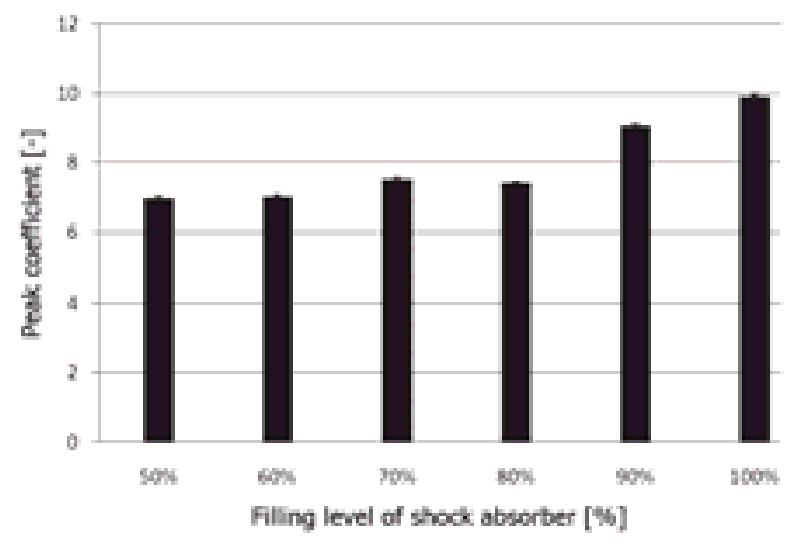

b) Peak coefficient

Fig. 11. Calculated estimators for acceleration signal in the running out of test stand obtained for the resonance frequency of the unsprung masses versus the shock absorber fluid loss - signal after PMD 


\section{Summary}

The results of analysis allow for the adoption of the following conclusions:

1) Vibration signals from the upper shock mount can be used to obtain diagnostic information on the technical state of shock absorber.

2) The PMD signal processing method allows for the effective conversion of non-stationary, transient signals to the quasi-stationary signal.

3) PMD method allows obtaining the FFT spectra with good spectral selectivity and proper location of the resonance frequency.

4) Secondary signals obtained after treatment with PMD shows the diagnostic sensitivity as a function of shock absorber fluid loss.

5) The PMD method and the analysis made so far can be used to supplement vehicle inspection stations EUSAMA method for quantitative identification of possible damage in the form of shock absorber fluid loss.

\section{References}

[1] Gardulski, J., Bezstanowiskowa metoda oceny stanu technicznego zawieszeń samochodów osobowych, Wydawnictwo Instytutu Technologii Eksploatacji, Katowice-Radom 2003.

[2] Gardulski, J., Vibroacoustic information processing system used in diagnostics of shock absorbers in passenger cars, Wydawnictwo Instytutu Technologii Eksploatacji, KatowiceRadom 2009.

[3] Potyka, D., Wptyw ubytku płynu amortyzatorowego na wartość skuteczności thmienia badana metoda EUSAMA, Projekt inżynierski, Katowice 2010.

[4] Sobczak, P., Wibroakustyczny system diagnozowania hydraulicznych amortyzatorów teleskopowych samochodów osobowych - Rozprawa Doktorska, Promotor: prof. dr hab. inż. Janusz Gardulski, Katowice 2012.

[5] Sobczak, P., Współczesne możliwości tworzenia oprogramowania modułów akwizycji danych, VI Studencka Sesja Naukowa, Katowice 2009.

[6] Sobczak, P., Gardulski, J., Weryfikacja Procedury Macierzowej Decymacji z wykorzystaniem sygnałów testowych, XXXIX Ogólnopolskie Sympozjum Diagnostyka Maszyn, Wisła 2012.

[7] Zembowicz, J., Fiat Seicento, WKiŁ, 2007. 